\title{
Emerging and re-emerging infectious disease threats in South Asia: status, vulnerability, preparedness, and outlook
}

\author{
Without investment in surveillance and early detection the region remains vulnerable to \\ infectious disease threats, say Buddha Basnyat and colleagues
}

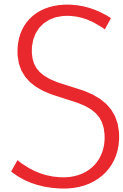

outh Asia, despite decreasing rates of infectious disease, accounts for a significant proportion of their global burden. The sub-continent is also in the midst of rapid economic growth; large scale changes in land use, access to water and sanitation, and agricultural production; environmental degradation; and technological transformation, all against a background of uneven health system capacity. South Asia, defined by the World Bank as Afghanistan, Bangladesh, Bhutan, India, Maldives, Nepal, Pakistan, and Sri Lanka, is home to a quarter of the world's population. Existing infectious disease challenges-including tuberculosis, HIV, and malaria-have been augmented by emerging and growing threats such as dengue, chikungunya, healthcare associated infections, and antimicrobial resistance. These emerging and re-emerging infectious disease challenges threaten to create economic disruption and potentially large morbidity and mortality burdens. Here we review the status, vulnerability, and preparedness for emerging and re-emerging infectious diseases and describe the state of preparedness and surveillance for threats such as Zika, Middle East respiratory syndrome coronavirus (MERS-CoV), and avian influenza.

Although there are frequent reports of sporadic cases of suspected emerging infectious disease syndromes and limited outbreaks of emerging infections such as Nipah

\section{KEY MESSAGES:}

- South Asia accounts for a significant proportion of the global burden of infection diseases, although in recent history it has not experienced a large outbreak of an emerging infection.

- The region remains seriously vulnerable to existing and new threats including Zika, Ebola, MERS-CoV, and avian influenza.

- Surveillance and preparedness for early detection of outbreaks is crucial in this region inhabited by one fourth of the world's population virus, Chandipura virus, and Crimean-Congo Haemorrhagic Fever (CCHF), South Asia has not in recent history experienced a large outbreak of an emerging infection. However, factors associated with vulnerability (Table 1) to the emergence of infectious diseases-such as population density, national and international travel, bio-diversity, land use change, zoonotic reservoirs, weak healthcare and public health systems, and deficiencies in water and sanitation-indicate that South Asia is at high risk. Preparedness and the ability to detect and respond to a disease outbreak are critical for national, regional, and global health security.

\section{Current status of emerging and epidemic infections}

We have focused on the diseases below as they include the most important emerging and re-emerging illnesses in South Asia. Enteric fever is often diagnosed in patients with fever but is increasingly difficult to treat with fluoroquinolones.

\section{Vector borne viral infections}

The main burden of vector borne viral infections in the region is attributable to dengue and chikungunya, while Zika virus is also likely to emerge. Of the 390 million dengue infections that are estimated to occur annually worldwide, over $70 \%$ occur in South Asia. $^{1}$

Although sporadic cases of dengue infection were seen in many South Asian countries in the 1960s, regular epidemics only occurred in the early 1990s in India and Sri Lanka. ${ }^{2}$ Dengue emerged in epidemic proportions in Bangladesh in 2000, ${ }^{3}$ in Pakistan in 2006, ${ }^{4}$ in Nepal in 2010, ${ }^{5}$ and more recently in Bhutan in 2013. ${ }^{6}$ In India and Sri Lanka, by around 40 years of age $90 \%$ to $95 \%$ of adults have been infected with the dengue virus, while $41 \%$ have been infected with chikungunya. ${ }^{27}$ Although the majority of dengue infections are inapparent, the majority of chikungunya infections appear to be symptomatic. ${ }^{7}$ In many countries, dengue, which was once a childhood infection, is increasingly seen in adults. ${ }^{8}$
The incidence of chikungunya in South Asian countries is lower than dengue and since there is only one serotype, people do not experience repeated infections. ${ }^{7}$ Almost all chikungunya infections, however, are symptomatic and some people develop disabling polyarthritis which can last for several months. ${ }^{9}$ Co-infection with these two viruses appears to occur often, possibly as both viruses are transmitted by the same vector Aedes aegypti. ${ }^{9}$ It is concerning that the Zika virus is also transmitted by the same vector, which is abundant in all South Asian countries. If Zika is introduced to the region it is likely to spread quickly, cause complications in pregnancies, and add to the burden of neurological infections caused by other flavi-viruses such as the West Nile virus and the Japanese Encephalitis virus.

\section{Zoonotic infections}

South Asia has been identified as a hot spot for the emergence of zoonotic infectious diseases. ${ }^{1011}$ The endemic zoonoses have re-emerged or emerged in newer areas or with newer clinico-epidemiological presentations, often with more serious manifestations.

Livestock may act as intermediate amplifying hosts, facilitating the transfer of pathogens from their normal ecological niche into humans. Examples are Japanese encephalitis (JE), Nipah virus, and Crimean-Congo haemorrhagic fever (CCHF). JE has spread to newer areas in the subcontinent against a backdrop of a large proportion of undiagnosed cases of acute encephalitis syndrome. ${ }^{12} \mathrm{JE}$ has become endemic to the Kathmandu valley region after its introduction in early $2000 . .^{13}$ Nipah virus emerged in Malaysia in the late 1990's, initially being misdiagnosed as JE, and there have since been frequent outbreaks in Bangladesh and, to a lesser extent, India. CCHF has recently been recognised in humans in South Asia for the first time. ${ }^{1415}$

The highly pathogenic avian influenza (HPAI) virus A/H5N1, which was introduced to the subcontinent in 2005 through wild birds, has since become endemic across large parts of north east India and Bangladesh, across porous international borders. 


\begin{tabular}{|c|c|c|}
\hline Factor & Situation in South Asia & Association with vulnerability to emerging and epidemic infections \\
\hline $\begin{array}{l}\text { Population size and } \\
\text { density }\end{array}$ & $\begin{array}{l}\text { South Asia is home to one quarter of world's population, with } \\
\text { Bangladesh and India being amongst the most densely } \\
\text { populated countries in the world }\end{array}$ & $\begin{array}{l}\text { Absolute population size and the intensity of contact between people are } \\
\text { key determinants-along with transmissibility of the infectious agent and } \\
\text { the susceptibility of the population to infection-that determine the scale } \\
\text { of an outbreak of an infection that is transmitted from person to person }\end{array}$ \\
\hline Land use & $\begin{array}{l}\text { The rate of land use change in most of South Asia is now slow. } \\
\text { Where land can be agriculturalised it has been, and much of the } \\
\text { land is already extensively cropped. The rate of forest growth is } \\
\text { positive in India, there being net reforestation. }\end{array}$ & $\begin{array}{l}\text { Changes in land use may alter ecosystems and the interaction of animal } \\
\text { hosts with humans, giving rise to new opportunities for amplification and / } \\
\text { or spill over to humans }{ }^{56}\end{array}$ \\
\hline Biodiversity ${ }^{57}$ & $\begin{array}{l}\text { South Asia is not especially bio-diverse but India may be a hot } \\
\text { spot of bat to human virus sharing }{ }^{58}\end{array}$ & $\begin{array}{l}\text { The impact of declining biodiversity is variable, and may act to either } \\
\text { increase or decrease the emergence of infectious diseases }\end{array}$ \\
\hline Insect and tick vectors ${ }^{59}$ & $\begin{array}{l}\text { Mosquito and tick vectors are widely present for some serious } \\
\text { infections }{ }^{60} .62\end{array}$ & $\begin{array}{l}\text { As Zika virus has shown, the presence of competent vectors can lead to } \\
\text { dramatic introductions and transmission of pathogens }\end{array}$ \\
\hline Livestock density & $\begin{array}{l}\text { Cattle and goats are raised in large numbers across South Asia. } \\
\text { As incomes increase the demand for meat will increase and } \\
\text { livestock farming will intensify }\end{array}$ & $\begin{array}{l}\text { Livestock may act as intermediate hosts for a range of zoonotic infections } \\
\text { including CCHF, fascioliasis, bovine TB, brucellosis, and leptospirosis from } \\
\text { cattle; and fascioliasis, brucellosis, Orf virus, and Q fever from sheep. Rift } \\
\text { Valley fever could be introduced successfully to South Asia'63 }\end{array}$ \\
\hline $\begin{array}{l}\text { Poverty and human } \\
\text { development index }\end{array}$ & $\begin{array}{l}\text { South Asia has had a period of sustained economic growth, } \\
\text { declining poverty rates, and improved human development. } \\
\text { Nevertheless the region is home to a very large number of poor } \\
\text { people with poor infrastructure }\end{array}$ & $\begin{array}{l}\text { Poverty is a risk factor for almost every infection, but is a particular } \\
\text { vulnerability for epidemic infections. Poverty is associated with crowding, } \\
\text { poor sanitation, poor nutrition, and poor access to preventive, diagnostic, } \\
\text { and therapeutic healthcare. It is no coincidence that Ebola raged out of } \\
\text { control in three of the poorest countries in Africa }\end{array}$ \\
\hline Healthcare systems & $\begin{array}{l}\text { The public healthcare systems in South Asia are poor, with } \\
\text { patchy coverage, limited resources, overcrowding, and } \\
\text { inadequate infrastructure }\end{array}$ & $\begin{array}{l}\text { Healthcare systems can contribute to the emergence and transmission of } \\
\text { infectious diseases in several ways: } \\
\text { - Resistance to antibacterial, antiviral, and anti-malarial drugs can be } \\
\text { promoted by poor use of these drugs } \\
\text { - Healthcare settings can amplify infections. The introduction and } \\
\text { transmission of MERS-CoV in Korea is a good example }\end{array}$ \\
\hline
\end{tabular}

It has resulted in losses of around US\$500 million (£398m; €460m). ${ }^{16-18}$ Rates of neuroleptospirosis and leptospirosis have been rising in north India and Sri Lanka and have been associated with disseminated intravascular coagulation. ${ }^{1920}$ The growing proportion of severe cases of leptospirosis has created massive pressures on the healthcare delivery systems in affected countries. ${ }^{21}$

Scrub typhus, which has been grossly under reported in South East Asian countries, ${ }^{22}$ is now increasingly being seen in newer ecological niches such as urban landscapes. ${ }^{23-25}$ Anthrax is endemic in large parts of South Asia. In the border areas of India, Bangladesh, and Myanmar, poor vaccination and surveillance have been accompanied by increasing anthrax cases, which prompted Bangladesh to announce a "red alert" in 2010. ${ }^{26}$

Rabies remains endemic in eight countries in South East Asia, with 1.4 billion people at risk. The region contributes about $45 \%$ of global rabies deaths, while the rhetoric on elimination continues to grow. ${ }^{2728}$ Brucellosis, bovine tuberculosis, and a range of food borne diseases contribute to the morbidity and mortality attributable to zoonotic infections but are struggling to gain the attention of policy makers in the subcontinent, ${ }^{29} 30$ despite resulting in 150 million illnesses, 175000 deaths, and 12 million disability adjusted life years. ${ }^{31}$

Enteric fever and antimicrobial resistance Enteric (typhoid) fever is caused by bacteria Salmonella typhi and Salmonella paratyphi. ${ }^{32} S$ typhi is the most common bacterial organism grown in blood cultures in South Asia. These organisms cause indistinguish- able clinical features that generally comprise of high fever for at least 3 days with no localising signs. ${ }^{33}$

Typhoid fever is one of the most common diagnoses in cases of fever in the region. Blood cultures (the gold standard for the diagnosis of typhoid fever) are not readily available in most, especially rural, regions of South Asia. Instead the widely available Widal test, a slide agglutination test developed in 1896, is often used to make a definitive diagnosis of enteric fever. ${ }^{34}$ Unfortunately, it is difficult to establish a "cut off" for this test. The test also cross reacts with malaria parasites, rickettsial organisms, and dengue virus, all very common causes of undifferentiated febrile illness in South Asia.

The use of the Widal test has sometimes had dire consequences, such as when outbreaks of scrub typhus in Nepal were mistakenly diagnosed as enteric fever and suboptimal treatment with ceftriaxone administered. ${ }^{35}{ }^{36}$ Finally, even where blood culture facilities are available, because of the paucity of the typhoid organism in the blood, blood culture growth is usually restricted to about $50 \%$. So without proper diagnostics, it is hard not only to prescribe appropriate treatment but also to estimate the true burden of typhoid fever in South Asia.

In recent years, the appearance in South Asia of fluoroquinolone resistant $\mathrm{H} 58$ typhoid organisms has made the treatment of this disease even more challenging. ${ }^{37}$

\section{Polio}

The elimination of polio from many countries in the region, most recently in India, is a landmark achievement. However, two out of the three remaining countries in the world with endemic polio are in South Asia. There were only 74 wild type polio cases in Pakistan and Afghanistan in 2015, and 33 in 2016. However, unrest in these countries threatens progress in eradication and is a high priority for regional cooperation.

\section{Vulnerabilities of South Asia}

South Asia already has some of the most densely populated areas in the world and is projected to see rapid shifts in urbanisation, population density, dietary patterns, and subsequent demand for animal source foods and agriculture intensification-all of which are considered important drivers of zoonoses. $^{38}$ While these factors are also indicators of economic growth, human and animal healthcare systems have failed to keep pace with the corresponding need for sectoral and intersectoral surveillance and coordination. ${ }^{39}$

Institutional capacity for epidemiological and laboratory response, especially at sub-national levels, remains limited, more so in veterinary sectors. Surveillance systems often are incomplete in their reach, fail to identify early warning signals, and communicate poorly across sectors. Despite the visibility following emergence of HPAI, limited capacity and infrastructure has kept wildlife departments in most countries from being active participants in preparedness and response efforts.

The outbreak of MERS-CoV in South Korea in 2015 served as a warning about the vulnerability to infectious disease outbreaks of overstretched, crowded, and unprepared healthcare systems. ${ }^{40}$ Healthcare systems 
are variable, but in South Asia there are the substantial challenges of inadequate infrastructure, poor quality services, fragmented health information systems, and weak controls over the private healthcare sector. ${ }^{41}$ This poses a risk of the late detection, and potentially explosive amplification, of epidemic prone infections within the healthcare system.

Fundamentally, the current state of affairs in the subcontinent flows from severe policy neglect. The One Health initiative is a worldwide, cross-sector approach to addressing vector borne and zoonotic diseases. While the world has moved towards incorporating One Health in their policy discourse, South Asia has been slow to adopt this approach, except for initial signs in Bangladesh. ${ }^{42}$ There have been limited efforts to build One Health capacity in the subcontinent, initiated mostly by external agencies, ${ }^{43}$ but policymakers remain disengaged in the absence of a convincing case made by the research community. ${ }^{445}$ This disconnect is further exemplified by the fact that veterinary research has focused more on increasing animal productivity, while neglecting zoonotic potential. ${ }^{46}$

The trepidations experienced during the outbreaks of Ebola in West Africa and subsequently during Zika cases in South America is justified given the fact that, if a rapidly spreading infection finds its way into South Asia, it could wreak havoc before being brought under control. ${ }^{47}$

\section{Preparedness}

There is limited regional capacity to identify, respond to, and mitigate emerging infectious disease threats in South Asia. The main reason seems to be a lack of political will. While mechanisms for regional collective conversations do exist, they have not translated into the kind of operational capabilities that the European Centers for Disease Prevention and Control or the European Commission are able to facilitate within the European Union. Moreover, the composition of the World Health Organization's South East Asia Regional Office leaves out key countries (Afghanistan and Pakistan) in the region, hindering cooperation at WHO level.

Clearly civil societies and research communities in the region need to work together to tackle these risks and vulnerabilities and to lobby for more political commitment. Multiple approaches need to be considered to overcome the limited preparedness of the region. ${ }^{48}$

Regional cooperative surveillance programmes, such as those promoted by the Connecting Organizations for Regional Surveillance (CORDS) initiative, may strengthen regional surveillance and preparedness. The South Asian Association for Regional Coop- eration (SAARC) should be activated and work alongside inter-governmental agencies such as WHO, the Food and Agriculture Organization of the United Nations, and the World Organization for Animal Health.

The European Commission and the European Developing Countries Clinical Trials Partnership (EDCTP) have supported the establishment of regional clinical research networks for emerging and epidemic prone infectious diseases in Europe, Latin America, and Africa. A major regional funding initiative is needed to establish a similar, sister clinical research network in South Asia that can tackle the combined threats of antimicrobial resistance and epidemic prone infections. However, especially in the context of South Asia, public health research, including systems and policy research, should not take a back seat to clinical research.

The fragmentation of prevention measures and the need to break the traditional governance silos of human and animal health systems is a significant challenge. Facets of the response may include establishing harmonised international commitments to enforce minimal assurances to confront zoonoses ${ }^{49}$; establishing effective intersectoral coordination measures without adversely reducing the core competencies of participating agencies; devising acceptable, effective, and sustainable policies, including trade laws, that tackle risks without endangering livelihoods; and investment in human and animal healthcare capacity at individual (caregivers) and systems (infrastructure) levels.

At the global scale, South Asia must become more engaged in the health security agenda. The government of India is a founder contributor to the Coalition for Epidemic Preparedness Innovation (CEPI), an initiative that aims to accelerate the development of new vaccines for high threat pathogens. This leadership is commendable, but such research and development pipelines needs to be linked to strengthened surveillance, response, and research platforms within South Asia to ensure that it can be evaluated and implemented locally. Finally, global science communities can help enhance regional conversation to encourage local collaboration.

Tackling these systemic shortcomings needs a concerted approach that takes a medium to long term view of outcomes. Focus should be on building strong, intersectorally connected systems, with aligned policies driven by One Health, as institutions come together to review programmes and policies.

\section{Outlook}

Early detection of outbreaks is crucial for their early control. Mathematical models have suggested that it might be possible to contain an emerging pandemic of avian influenza if detection and reporting of cases that suggest human to human transmission happen within around three weeks of the first case. ${ }^{5051}$ A report in 2010 of 398 WHO notified outbreaks that happened between 1996 and 2009 found that only 7\% occurred in the WHO South East Asia region and that, over the period studied, the timeliness of detection had improved, although significant delays in public notification remained..$^{52}$ A 2016 update has not changed the overall picture. ${ }^{53}$ This implies that outbreaks in South Asia are less common than elsewhere, since the WHO South East Asia region has around $27 \%$ of the world population yet only $7 \%$ of reported outbreaks. This is surprising given that the characteristics of South Asia show its vulnerability to emerging and epidemic infections. We must not ignore this warning that outbreaks are less well detected and reported in this region.

The revised International Health Regulations (IHR) whose aim is to help the international community prevent and respond to acute public health risks that can cross borders was implemented in 2007. They appear to have had a positive effect on detection and reporting, and the latest data on IHR core capacities (2013) shows good levels in South East Asia. ${ }^{5254}$ This indicated that the region is well prepared. However the core capacity indicators have been criticised..$^{55}$

Clearly, there has been insufficient work on epidemic preparedness in South Asia. Unless immediate attention is given to preparedness and ability to respond, the region remains vulnerable to existing and new threats including Zika, Nipah, MERS-CoV, and avian influenza.

Contributors and sources: All the authors contributed to the initial draft. RL put the segments of the contribution together. PH outlined the table. All the authors worked on and approved the final version.

Competing interests: We have read and understood BMJ's policy on declaration of interests and declare no conflict of interest.

Provenance and peer review: Commissioned; externally peer reviewed

Ramanan Laxminarayan, ${ }^{1,2}$

Manish Kakkar, ${ }^{3}$

Peter Horby, 4

Gathsaurie Neelika Malavige,4,5

Buddha Basnyat ${ }^{4,6,7}$

${ }^{1}$ Center for Disease Dynamics, Economics, and Policy, Washington, DC, USA

2Princeton Environmental Institute, Princeton University, Princeton, New Jersey, USA

${ }^{3}$ Public Health Foundation of India, New Delhi, India

${ }^{4}$ Centre for Tropical Medicine and Global Health,

Nuffield Department of Clinical Medicine, University of Oxford, UK

${ }^{5}$ Faculty of Medical Sciences, University of Sri Jayawardanapura, Sri Lanka

${ }^{6}$ Oxford University Clinical Research Unit, Patan Academy of Health Sciences, Lalitpur, Nepal

${ }^{7}$ Global Antibiotic Resistance Partnership, Nepal buddha.basnyat@ndm.ox.ac.uk 
1 Bhatt S, Gething PW, Brady OJ, et al. The global distribution and burden of dengue. Nature 2013:496:504-7. doi:10.1038/nature12060.

2 Jeewandara C, Gomes L, Paranavitane SA, et al. Change in dengue and Japanese encephalitis seroprevalence rates in Sri Lanka. PLoS One 2015;10:e0144799. doi:10.1371/journal.pone.0144799.

3 Sharmin S, Viennet E, Glass K, Harley D. The emergence of dengue in Bangladesh: epidemiology, challenges and future disease risk. Trans R Soc Trop Med Hyg 2015;109:619-27. doi:10.1093/trstmh/trv067.

4 Pandey BD, Morita K, Khanal SR, et al. Dengue virus, Nepal. Emerg Infect Dis 2008;14:514-5. doi:10.3201/ eid1403.070473.

5 Subedi D, Taylor-Robinson AW. Epidemiology of dengue in Nepal: History of incidence, current prevalence and strategies for future control. J Vector Borne Dis 2016;53:1-7.

6 Zangmo S, Klungthong C, Chinnawirotpisan P, et al. Epidemiological and molecular characterization of dengue virus circulating in Bhutan, 2013-2014. PLoS Negl Trop Dis 2015;9:e0004010. doi:10.1371/journal. pntd.0004010.

7 Rodríguez-Barraquer I, Solomon SS, Kuganantham P, et al. The hidden burden of dengue and Chikungunya in Chennai, India. PLoS Negl Trop Dis 2015;9:e0003906. doi:10.1371/journal. pntd.0003906.

8 Pang J, Leo YS, Lye DC. Critical care for dengue in adult patients: an overview of current knowledge and future challenges. Curr Opin Crit Care 2016;22:485-90. doi:10.1097/MCC.0000000000000339.

9 Saswat T, Kumar A, Kumar S, et al. High rates of co-infection of Dengue and Chikungunya virus in Odisha and Maharashtra, India during 2013. Infect Genet Evol 2015;35:134-41. doi:10.1016/j. meegid.2015.08.006.

10 Jones KE, Patel NG, Levy MA, et al. Global trends in emerging infectious diseases. Nature 2008;451:990-3. doi:10.1038/nature06536.

11 Grace DMF, Ochungo P, Kruska R, et al. Mapping of poverty and likely zoonoses hotspots. 2012. https:// cgspace.cgiar.org/handle/10568/21161.

12 National Vector Borne Disease Control Program. Japanese encephalitis. 2015. http://nvbdcp.gov.in/ je-new.html.

13 Partridge J, Ghimire P, Sedai T, Bista MB, Banerjee M. Endemic Japanese encephalitis in the Kathmandu valley, Nepal. Am J Trop Med Hyg 2007;77:1146-9

14 Yadav PDRC, Patil DY. D Majumdar T, Mourya DT. Crimean-Congo hemorrhagic fever: current scenario in India. Proc Natl Acad Sci, India, Sect B Biol Sci 2014;84:9-18doi:10.1007/s40011-013-0197-3.

15 Hussain B, Iqbal A, Abudakar M. Crimean-Congo hemorrhagic fever (CCHF): an emerging disease in Pakistan. Vetenary Sciences: Research and Reviews 2016:2:11-22

16 World Health Organization. H5N1 avian influenza: timeline of major events. 2014. www.who.int/ influenza/human_animal_interface/avian_influenza/ H5N1 avian influenza update.pdf.

17 Chakrabarti AKPS, Pawar SD, Cherian SS, et al. Characterization of the influenza A H5N1 viruses of the 2008-09 outbreaks in India reveals a third introduction and possible endemicity. PLoS One 2009;4:e7846. doi:10.1371/journal.pone.0007846.

18 Marinova-Petkova A, Feeroz MM, Rabiul Alam SM, et al. Multiple introductions of highly pathogenic avian influenza $\mathrm{H} 5 \mathrm{~N} 1$ viruses into Bangladesh. Emerg Microbes Infect 2014;3:e11. doi:10.1038/ emi.2014.11.

19 Sethi S, Sharma N, Kakkar N, et al. Increasing trends of leptospirosis in northern India: a clinico-epidemiological study. PLoS Negl Trop Dis 2010:4:e579 doi:10.1371/journal.pntd.0000579.

20 Bandara M, Ananda M, Wickramage K, Berger E, Agampodi S. Globalization of leptospirosis through travel and migration. Global Health 2014;10:61. doi:10.1186/s12992-014-0061-0.

21 Schneider MCJM, Jancloes M, Buss DF, et al. Leptospirosis: a silent epidemic disease. Int J Environ Res Public Health 2013;10:7229-34. doi:10.3390/ ijerph10127229.
22 Aung AKSD, Spelman DW, Murray RJ, Graves S. Rickettsial infections in Southeast Asia: implications for local populace and febrile returned travelers. Am Trop Med Hyg 2014;91:451-60. doi:10.4269/ ajtmh.14-0191

23 Park S-WHN-Y, Ha NY, Ryu B, et al. Urbanization of scrub typhus disease in South Korea. PLoS Negl Trop Dis 2015;9:e0003814. doi:10.1371/journal. pntd.0003814

24 Wei Y, Huang Y, Luo L, Xiao X, Liu L, Yang Z. Rapid increase of scrub typhus: an epidemiology and spatial-temporal cluster analysis in Guangzhou City, Southern China, 2006-2012. PLoS One 2014;9:e101976. doi:10.1371/journal.pone.0101976.

25 Sethi S, Prasad A, Biswal M, et al. Outbreak of scrub typhus in North India: a re-emerging epidemic. Trop Doct 2014:44:156-9. doi:10.1177/0049475514523761.

26 Mondal SP, Yamage M. A retrospective study on the epidemiology of anthrax, foot and mouth disease, haemorrhagic septicaemia, peste des petits ruminants and rabies in Bangladesh, 2010-2012. PLoS One 2014:9:e104435, doi:10.1371/journal. pone. 0104435

27 Gongal G, Wright AE. Human rabies in the WHO Southeast Asia Region: forward steps for elimination. Adv Prev Med 2011; 1:383870. doi: $10.4061 / 2011 / 383870$

28 Chowdhury F-RBA, Basher A, Amin MR, Hassan N, Patwary MI. Rabies in South Asia: fighting for elimination. Recent Pat Antiinfect Drug Discov 2015:10:30-4 doi:10.2174/15748 91X10666150410130024.

29 Falenski A, Mayer-Scholl A, Filter M, Göllner C, Appel B, Nöckler K. Survival of Brucella spp. in mineral water, milk and yogurt. Int J Food Microbiol 2011;145:326-30. doi:10.1016/i.ijfoodmicro.2010.11.033.

30 Thakur ASM, Katoch VC, Dhar P, Katoch RC. A study on the prevalence of bovine tuberculosis in farmed dairy cattle in Himachal Pradesh.Veterinary World, 2010.

31 Coker RJHB, Hunter BM, Rudge JW, Liverani M, Hanvoravongchai P. Emerging infectious diseases in southeast Asia: regional challenges to control. Lancet 2011;377:599-609. doi:10.1016/ S0140-6736(10)62004-1.

32 Parry C, Basnyat B. Typhoid and paratyphoid fevers. In: Warrell D, Cox TM, Firth JD, eds. Oxford Textbook of Medicine.5th ed. Oxford University Press, 2010doi:10.1093/ med/9780199204854.003.070608 update 002.

33 Maskey AP, Day JN, Phung QT, et al. Salmonella enterica serovar Paratyphi A and S. enterica serova Typhi cause indistinguishable clinical syndromes in Kathmandu, Nepal. Clin Infect Dis 2006:42:1247-53. doi:10.1086/503033.

34 Olopoenia LA, King AL. Widal agglutination test - 100 years later: still plagued by controversy. Postgrad Med 2000;76:80-4. doi:10.1136/pmj.76.892.80.

35 Basnyat B. Typhoid versus typhus fever in post earthquake Nepal. Lancet Glob Health 2016;4:e516-7. doi:10.1016/S2214-109X(16)30094-8

36 Arjyal A, Basnyat B, Nhan HT, et al. Gatifloxacin versus ceftriaxone for uncomplicated enteric fever in Nepal: an open-label, two-centre, randomised controlled trial. Lancet Infect Dis 2016;;16:535-45. doi:10.1016/ S1473-3099(15)00530-7.

37 Ryan ET. Troubling news from Asia about treating enteric fever: a coming storm. Lancet Infect Dis 2016;16:508-9. doi:10.1016/S1473-3099(15)00542-3.

38 Regmi ADJ. Effects of urbanization on global food demand. 2013. https://naldc.nal.usda.gov/naldc/ download. . httml?id=34108\&content=PDF.

39 Chatterjee P, Kakkar M, Chaturvedi S. Integrating one health in national health policies of developing countries: India's lost opportunities. Infect Dis Poverty 2016;5:87. doi:10.1186/s40249-016-0181-2

40 Cowling BJ, Park M, Fang VJ, Wu P, Leung GM, Wu JT. Preliminary epidemiological assessment of MERS-CoV outbreak in South Korea, May to June 2015. Euro Surveill 2015;20(25):7-13.

41 Patel V, Parikh R, Nandraj S, et al. Assuring health coverage for all in India. Lancet 2015;386:2422-35 doi:10.1016/S0140-6736(15)00955-1.

42 Institute of Epidemiology Disease Control and Research. Strategic framework for One Health approach to infectious diseases in Bangladesh. 2012.
43 Nguyen-Viet H, Doria S, Tung DX, Mallee H, Wilcox BA, Grace D. Ecohealth research in Southeast Asia: past, present and the way forward. Infect Dis Poverty 2015;4:5. doi:10.1186/2049-9957-4-5.

44 Abbas SSKM, Kakkar M. Rabies control in India: a need to close the gap between research and policy. Bull World Health Organ 2015:93:131-2. doi:10.2471/ BLT.14.140723.

45 Kakkar M, Venkataramanan V, Krishnan S, Chauhan RS, Abbas SS. Roadmap to Combat Zoonoses in India (RCZI) initiative. Moving from rabies research to rabies control: lessons from India. PLoS Negl Trop Dis 2012;6:e1748. doi:10.1371/journal.pntd.0001748.

46 Thomas D, Zerbini E, Parthasarathy R, Vaidyanathan A. Increasing animal productivity on small mixed farms in South Asia: a systems perspective. Agric Syst 2002-71:41-57doi:10.1016/S0308-521X(01)00035-X.

47 Eisenstein M. Disease: Poverty and pathogens. Nature 2016;531:S61-3. doi:10.1038/531S61a.

48 Governance challenges for zoonotic disease surveillance, reporting and response. InKeusch GTPM, Gonzalez MC, Scott KA, Tsai P, eds. Sustaining global surveillance and response to emerging zoonotic diseases. National Academies Press, 2009: 205-33.

49 Sekar N, Shah NK, Abbas SS, Kakkar M. Roadmap to Combat Zoonoses in India Initiative. Research options for controlling zoonotic disease in India, 2010-2015. PLoS One 2011;6:e17120. doi:10.1371/journal.pone.0017120.

50 Longini IM Jr, , Nizam A, Xu S, et al. Containing pandemic influenza at the source. Science 2005:309:1083-7. doi:10.1126/science.1115717.

51 Ferguson NM, Cummings DAT, Cauchemez S, et al. Strategies for containing an emerging influenza pandemic in Southeast Asia. Nature 2005;437:209-14. doi:10.1038/nature04017.

52 Chan EH, Brewer TF, Madoff LC, et al. Global capacity for emerging infectious disease detection. Proc Natl Acad Sci U S A 2010;107:21701-6. doi:10.1073/ pnas.1006219107.

53 Kluberg SA, Mekaru SR, Mclver DJ, et al. Global Capacity for Emerging Infectious Disease Detection, 1996-2014. Emerg Infect Dis 2016;22:E1-6. doi:10.3201/eid2210.151956.

54 Hardiman M. The revised International Health Regulations: a framework for global health security. Int J Antimicrob Agents 2003;21:207-11. doi:10.1016/ S0924-8579(02)00294-7.

55 ljaz K, Kasowski E, Arthur RR, Angulo FJ, Dowell SF. International Health Regulations--what gets measured gets done. Emerg Infect Dis 2012;18:1054-7. doi:10.3201/eid1807.120487.

56 McMichael AJ. Environmental and social influences on emerging infectious diseases: past, present and future. Philos Trans R Soc Lond B Biol Sci 2004:359:1049-58. doi:10.1098/rstb.2004.1480.

57 Keesing F, Belden LK, Daszak P, et al. Impacts of biodiversity on the emergence and transmission of infectious diseases. Nature 2010;468:647-52. doi:10.1038/nature09575.

58 Brierley L, Vonhof MJ, Olival KJ, Daszak P, Jones KE. Quantifying Global Drivers of Zoonotic Bat Viruses: A Process-Based Perspective. Am Nat 2016;187:E53-64. doi:10.1086/684391.

59 Kilpatrick AM, Randolph SE. Drivers, dynamics, and control of emerging vector-borne zoonotic diseases. Lancet 2012;380:1946-55. doi:10.1016/ S0140-6736(12)61151-9.

60 Ghosh S, Nagar G. Problem of ticks and tick-borne diseases in India with special emphasis on progress in tick control research: a review. J Vector Borne Dis 2014;51:259-70

61 Dhiman RC. Emerging vector-borne zoonoses: eco-epidemiology and public health implications in India. Front Public Health 2014;2:168. doi:10.3389/ fpubh.2014.00168.

62 Dash AP, Bhatia R, Sunyoto T, Mourya DT. Emerging and re-emerging arboviral diseases in Southeast Asia. I Vector Borne Dis 2013;50:77-84

63 Liverani M, Waage J, Barnett T, et al. Understanding and managing zoonotic risk in the new livestock industries. Environ Health Perspect 2013;121:873-7. doi:10.1289/ehp.1206001.

Cite this as: BMJ 2017;357:j1447

http://dx.doi.org/10.1136/bmj.j144 